\title{
Os jogos escolares como mecanismos de manutenção e eliminação: uma crítica à lógica esportiva na escola
}

Giovanni Frizzo*

\begin{abstract}
Resumo: Este artigo tem por objetivo analisar os mecanismos de manutenção e eliminação presentes nos Jogos Escolares, especialmente nas séries finais do ensino fundamental da Educação Básica, evidenciando a lógica esportiva na escola integrada ao projeto formativo escolar da atualidade. Através de uma pesquisa de caráter qualitativo na rede municipal de ensino de Nova Santa Rita, analisamos os Jogos Escolares que compõem o calendário escolar desta rede de ensino, identificando a lógica esportiva integrada ao projeto formativo na escola.
\end{abstract}

Palavras-chave: Educação Física. Escola. Jogos Escolares

\section{INTRODUÇÃo}

O esporte como conteúdo predominante da educação física escolar já foi matéria de diversos estudos neste campo de investigação, principalmente em uma perspectiva crítica, tais como os estudos de Hildebrandt-Stramann (2001), Bracht (2005), Oliveira (2001), Kunz (2004) e Souza (2009). De maneira geral, estes autores apontam a existência de uma certa identidade histórica entre a educação física e o esporte, como sinônimos do trato desta disciplina na escola. A partir das conclusões destes estudos, é possível afirmar a existência de um certo consenso acerca das limitações existentes nas aulas de educação física ao abordar prioritariamente, ou somente, o esporte. Assim como, é possível também identificar nas produções referidas a crítica à redução do trato com o conhecimento esportivo à sua dimensão gestual e técnica, tendo como sentido a sobrepujança e a comparação objetiva (HILDEBRANDT-STRAMANN, 2001). Além da ressalva que Kunz (2004, p. 125) apresenta, de que "o

\footnotetext{
"Professor Adjunto, Escola Superior de Educação Física, Universidade Federal de Pelotas Pelotas, RS. E-mail: gfrizzo2@gmail.com
} 
esporte ensinado nas escolas enquanto cópia irrefletida do esporte competição ou de rendimento, só pode fomentar vivências de sucesso para uma minoria e o fracasso ou vivência de insucesso para a grande maioria". Esta forma de trabalhar com o conteúdo esporte nas aulas de educação física, sob o viés da competição, contribui sobremaneira para a adaptação e "naturalização" de relações individualistas e competitivas entre o alunado, onde convive-se com formas de inclusão e exclusão a partir de demandas que transcendem a forma escolar.

Ao longo das últimas décadas, esse caráter do esporte como sinônimo de educação física vem sendo reavaliado de forma crítica. Além disso, também há uma discussão importante no campo científico da educação física em relação à forma como o esporte se interpõe para as aulas de educação física na escola, nesta questão Carmem Soares et al. (1992, p. 70) aponta que:

[...] o esporte, como prática social que institucionaliza temas lúdicos da cultura corporal, se projeta numa dimensão complexa de fenômeno que envolve códigos, sentidos e significados da sociedade que o cria e o pratica. Por isso, deve ser analisado nos seus variados aspectos, para determinar a forma em que deve ser abordado pedagogicamente no sentido de esporte "da" escola e não como esporte "na" escola."

Uma possível causa desta esportivização da educação física diz respeito ao fato de que no decorrer da história as organizações esportivas criaram diversos mecanismos de parcerias com o poder público na qual a escola é uma das instituições que vai perceber modificações significativas em sua estrutura. Como aponta Souza (2009, p. 33),

[...] saúde, educação e integração constituíram-se, ao longo do tempo, em elementos que tornaram o esporte conteúdo central da educação física escolar, em que os objetivos do desenvolvimento esportivo presentes no espaço escolar, determinados pela prática da competição, não se distinguem dos objetivos do modelo esportivo de alto nível, como exemplo os Jogos Escolares. 
A partir da conclusão da autora, buscamos neste artigo analisar os mecanismos de manutenção e eliminação presentes nos Jogos Escolares, especialmente nas séries finais do ensino fundamental da Educação Básica, evidenciando a lógica esportiva na escola integrada ao projeto formativo escolar da atualidade.

Os mecanismos de manutenção e eliminação, sistematizados por Freitas (1995), tratam de analisar as formas de acesso e permanência na escola ao longo da Educação Básica condicionadas por relações de sua origem de classe social. Neste processo, as formas avaliativas adquirem centralidade para compreender como o alunado se relaciona com a formação escolar e quais elementos se interpõem para sua manutenção e/ou eliminação. Neste texto, tomamos como um destes elementos os Jogos Escolares.

Para realizar esta investigação, nos utilizamos de um aporte qualitativo de pesquisa, utilizando como fonte de informações a análise de documentos (analisamos os regulamentos dos Jogos Escolares do Rio Grande do Sul e do Guri Bom de Bola), a observação participante (da participação de todas as escolas do município durante a realização dos Jogos Escolares no ano de 2010), entrevistas com o professorado de educação física e questionário com os alunos e alunas. Realizamos a pesquisa na Rede Municipal de Ensino de Nova Santa Rita-RS (RMENSR), município localizado na região metropolitana de Porto Alegre, contemplando todas as seis escolas que oferecem a disciplina de educação física para as séries finais do ensino fundamental. Devido à este número reduzido de escolas municipais, foi possível que participassem do estudo todos os professores e professoras ${ }^{1}$ de educação física do município (composta por três professoras e cinco professores com idade entre 26 e 44 anos), além da participação de 307 alunos e alunas através de respostas aos questionários que realizamos (média de 51 alunos e alunas por escola).

${ }^{1}$ Os nomes das professoras e dos professores foram suprimidos para garantir o sigilo dos informantes que fizeram parte do estudo. 
Partindo do entendimento de que a realidade não é constituída por partes isoladas, e sim, da articulação entre o singular e o geral através do particular, o trato com as mediações nos permitiu compreender nexos e relações existentes entre os Jogos Escolares e a perspectiva de ser humano que a escola se propõe a formar, além das condições materiais e objetivas em que tal projeto formativo se consolida. Daí que, se justifica este objeto de investigação como parte dos processos de formação humana na escola e na educação física.

\section{Os Jogos Escolares como Política Educacional}

Historicamente, as competições esportivas escolares enquanto políticas públicas, no Brasil, tiveram a sua efetivação no ano de 1969 durante a ditadura empresarial-militar, através da Divisão de Educação Física do Ministério da Educação e Cultura, onde as competições eram chamadas de "Jogos Estudantis Brasileiros". No ano 2000, se modificou o nome dos jogos para "Olimpíadas Colegiais", que eram organizados pelo então Ministério da Educação, Esporte e Turismo em convênio com organizações privadas como o Comitê Olímpico Brasileiro e Rede Globo de Televisão. Em novembro deste mesmo ano, foi realizada a $1^{\text {a }}$ "Olimpíada Colegial Esperança" (chamada assim por causa do Projeto Criança Esperança, da Rede Globo). Desde então, as competições escolares fazem parte do calendário esportivo das Olimpíadas Escolares, que tem etapas seletivas municipais e estaduais classificatórias para as competições nacionais.

Durante o século passado, o setor governamental (em âmbito nacional) responsável pelo esporte foi modificado diversas vezes. Em 1970, esta Divisão foi transformada em Departamento de Educação Física e Desportos, ainda veiculada ao Ministério da Educação e Cultura. Em 1978, este Departamento foi transformado em Secretaria de Educação Física e Desporto ainda durante o regime militar, e assim permaneceu até 1989, quando Fernando Collor de Melo, em 1990, extingue a Secretaria ligada ao Ministério da 
Educação e cria a Secretaria de Desportos da Presidência da República. Após a saída de Collor, o esporte voltou a ser vinculado ao Ministério da Educação, com a Secretaria de Desportos. No Governo FHC foi criado o Ministério Extraordinário do Esporte e a antiga secretaria é transformada no INDESP - Instituto Nacional de Desenvolvimento do Desporto, desvinculado do MEC e subordinado ao Ministério Extraordinário do Esporte. Em seu segundo mandato, 1999, FHC cria o Ministério do Esporte e Turismo, o INDESP passa a ser vinculado a este órgão. Em outubro de 2000, o INDESP é extinto e substituído pela Secretaria Nacional do Esporte. No Governo Lula, as duas pastas: Esporte e Turismo, são separadas criando dois ministérios distintos - Ministério do Turismo e Ministério do Esporte.

Embora o atual Ministério dos Esportes seja divididos em três secretarias: Secretaria de Alto Rendimento; Secretaria de Esporte, Educação, Lazer e Inclusão Social; Secretaria de Futebol e Direitos do Torcedor, a secretaria responsável pela realização das competições escolares é a Secretaria de Alto Rendimento, já demonstrando que o caráter destas competições coaduna com o modelo institucionalizado de esporte competitivo, ao invés de comporem iniciativas de cunho educacional.

Os jogos escolares que acontecem na RMENSR provém de políticas públicas e privadas, são eles: Jogos Escolares do Rio Grande do Sul (JERGS) e Jogos Guri Bom de Bola. Enquanto política pública, os JERGS são organizados pela Secretaria da Educação do Rio Grande do Sul, através da Coordenação de Educação Física, Esporte e Lazer da Divisão de Programas e Projetos Especiais do Departamento Pedagógico, sendo executados pelas Coordenadorias Regionais de Educação junto às administrações municipais. São realizadas quatro etapas classificatórias ao longo de cada ano: municipal, coordenadoria, regional e final.

Os Jogos Guri Bom de Bola compõem o Projeto Bom de Bola promovido pelo Grupo Rede Brasil Sul (RBS), afiliada da Rede Globo de comunicações, executado pelas secretarias municipais de educação e coordenado pelo setor de eventos do Grupo RBS. É destinado às escolas da rede pública e privada de ensino, em três 
etapas: municipais, regionais e finais (nesta etapa regional, o Estado fica dividido em 12 regiões correspondentes às áreas de cobertura da RBS TV).

Embora oriundos de caracterização distinta entre público e privado, percebemos que estes jogos escolares têm objetivos e finalidades idênticas. Como podemos perceber no regulamento dos dois modelos de jogos escolares, no que se refere aos seus objetivos e finalidades:

Art. 05 - São objetivos dos JERGS:

I. Fomentar a prática do desporto educacional, contextualizando-o como meio de educação;

[...] III. Contribuir para o desenvolvimento integral do educando como ser social, estimulando o pleno exercício da cidadania, através do esporte;

IV. Fomentar a ocupação do tempo do educando, tendo por fim o acesso a essa prática;

[...] VI. Possibilitar a identificação de novos talentos esportivos (JERGS, 2010, p. 1) [grifos meus].

$-\mathrm{X}-$

Art. $3^{\circ}$ - São finalidades do Projeto Bom de Bola:

- Promover a continuidade do processo pedagógico vivenciado nas aulas de Educação Física;

- Desenvolver os princípios que norteiam o esporte educacional do Rio Grande do Sul: educação, integração, cooperação e participação.

- Situar a escola como centro esportivo e formativo da comunidade.

- Consolidar a parceria dos Governos Municipais com a iniciativa privada, em nível esportivo (GURI BOM DE BOLA, 2010, p. 9) [grifos meus].

Ainda na análise dos documentos destas competições é possível identificar a lógica competitiva do esporte de alto rendimento em 
que se baseiam. No regulamento do JERGS, um dos artigos referese à alunos e atletas como se fossem sinônimos: "Art. 15 - Cada atleta poderá participar de todas as modalidades, somente em sua categoria de origem, exceto os alunos nascidos em 1998 que poderão atuar nas categorias mirim e infantil" (JOGOS ESTUDANTIS DO RIO GRANDE DO SUL, 2010, p. 4) [grifos meus].

Percebe-se através destes excertos dos regulamentos algumas características basilares da lógica esportiva na escola, identificável em: a) ao pensar a escola como centro de formação de atletas ou lócus de identificação de talentos esportivos; b) entrelaçar a iniciativa privada e as políticas públicas como propositoras de uma mesma finalidade; c) tratar alunos e alunas das escolas públicas como atletas de competições escolares, sendo que os próprios documentos apontam a "preocupação" com o caráter pedagógicos da formação do alunado.

\section{A Relação dos Sujeitos com os Jogos Escolares}

Através dos diálogos que fizemos durante a investigação empírica e nos relatos do professorado durante as entrevistas, percebeu-se que os Jogos Escolares expõem divergentes interesses em torno dos objetivos que a gestão, professorado e alunado imprimem à eles. Por um lado, a gestão ${ }^{2}$ reproduz discursos de que os jogos escolares contribuem para a cidadania, saúde, participação, respeito às regras etc, além do interesse de colocar as escolas em disputa numa competição para obter algum tipo de êxito sobre as outras; por outro lado, o alunado quer disputar os jogos com o intuito de ganhar, de ser campeões, de serem melhores que as outras escolas, de poder tripudiar sobre os colegas que não foram jogar e sobre as escolas que perderam seus jogos, sendo a derrota e a vitória, momentos de decepção ou exaltação, não guardando relações de aprendizagem.

\footnotetext{
${ }^{2}$ Neste estudo, entende-se como a perspectiva da "gestão", as comissões organizadoras dos Jogos escolares e a Secretaria Municipal de Educação, Esporte e Cultura de Nova Santa Rita, onde seus objetivos relativos aos Jogos são expressos através dos documentos.
} 
Como podemos evidenciar no relato de uma das professoras entrevistadas: "por mais que tu conscientize eles que nós vamos participar, eles querem ganhar de qualquer jeito, aí tu vai lá, eles perdem e ficam: 'também professora a gente perdeu, a gente não treinou, a gente não fez isso, a gente não fez aquele outro' e todo ano é a mesma coisa"3

A reflexão do Professor F converge com esta ideia, afirmando também que esta prática com intuito somente competitivo promove a segregação entre o alunado, propondo que seja modificada a forma de realização dos Jogos:

[...] eu nunca parei pra pensar sobre isso, mas se tivesse como fazer de uma outra maneira, remodelar isso, dar outro objetivo pro final do torneio, mas não simplesmente dar medalha e ser campeão pra chacotear outro: "Te ganhei! Sou melhor que tu!". Ao invés de aproximar, eu acho que acaba segregando mais, se não tiver um pouco de cuidado, desperta muito a competitividade deles e acho que aqui não é o lugar apropriado pra isso" ${ }^{\prime 4}$.

Essa questão também foi observada ao analisarmos as respostas do alunado à pergunta: "o que você pensa sobre os Jogos Escolares?" Nas respostas dos questionários foi possível identificar que a maior parte do alunado (51\% dos questionários respondidos) expressou um caráter da competitividade e da possibilidade de tornar-se atleta no futuro como maior motivação à participação nos Jogos. Além disso, a lógica competitiva e individualista do modelo adotado, também faz com que o alunado perspective como uma oportunidade para "mostrar seu talento" esportivo, acreditando que estas competições permitem que empresários do esporte possam estar observando o aluno ou aluna que se destaca em alguma modalidade com o intuito de oferecer oportunidades para a carreira de atleta.

${ }^{3} \mathrm{FRIZZO}$, Giovanni. Informação pessoal: entrevista Professora B. 2010. ${ }^{4}$ FRIZZO, Giovanni. Informação pessoal: entrevista Professor F. 2010. 
Selecionamos alguns trechos dos questionários respondidos que são significativos das afirmações acima. Sobre a competitividade exacerbada, estes fragmentos esboçam esta noção: "temos que fazer o máximo possível para ganhar"; "tentar achar a escola que tem melhor desempenho dos meninos que jogam"; "quando a gente for jogar a gente tem que ser unidos e ir para ganhar"; "é bom porque podemos medir força com as outras escolas". Junto à esta questão, também há a necessidade do vir-a-ser que está presente no imaginário do alunado a respeito dos Jogos Escolares, quando vislumbram oportunidades de serem atletas quando jogam estas competições: "uma boa oportunidade de crescer na carreira de jogador, mas isso é um entre milhões competindo, impossível!"; "é um descobrimento de novos talentos para o futuro"; "dá uma chance para os guris que jogam, vai que tem um olheiro!"

As contradições existentes nas percepções entre a gestão, o professorado e o alunado acerca dos Jogos Escolares se encerram com o que pensa o professorado sobre a realização destas atividades. Percebemos que o professorado faz uma análise bastante crítica em relação à forma e a organização dos Jogos Escolares que ocorrem no município.

Segundo o Professor D, os jogos interferem negativamente na organização de suas aulas na escola, ao observar que

[...] é "juntação" de gente, é "pelada", é só pra dizer que fez alguma coisa. Aí tu perde de estar em sala de aula com alunos que precisam de um reforço, precisam de uma aula a mais para estar num campo, jogar duas partidas, $10 \mathrm{~h}$ tu está fora da competição e tem que esperar até meio dia o ônibus para voltar para escola. Pra mim isso é mal! [...] o propósito disso poderia ser outro 5 .

Uma das questões motivadoras das críticas do professorado é com relação à postura dos colegas quando estão jogando com suas equipes, a competitividade assume um caráter de disputa exacerbada,

${ }^{5}$ FRIZZO, Giovanni. Informação pessoal: entrevista Professor D. 2010.

Movimento, Porto Alegre, v. 19, n. 04, p. 163-180, out/dez de 2013. 
própria do modelo esportivo hegemônico difundido como mercadoria. Durante o acompanhamento do JERGS, junto à uma das equipes, registramos em nosso diário de campo a seguinte passagem:

No trajeto da escola para o ginásio, a professora comentou que em outro dia, um professor de outra escola a havia questionado sobre um aluno seu não ter a idade correta para jogar em categoria inferior. Com este fato, ela ficou bastante incomodada por ter desconfiado de sua postura profissional. $\mathrm{Na}$ ocasião, ela comprovou a idade correta de seu aluno e disse sentir-se desrespeitada pelo colega ${ }^{6}$.

O Professor D corrobora com esta crítica quando relata que: "se a proposta é integrar, socializar tanto professores como alunos, fica feio como no ano passado o pessoal arbitrando e o professor do lado fora: 'Tu tá me roubando! Porque tu trabalha na outra escola!' é sem propósito!"7.

A Professora E chama a atenção para o fato de que a lógica da competição e a forma de tratamento existente entre os colegas, não contribui para a formação do alunado e nem para as relações entre o professorado,

Era pra contribuir, mas sinceramente, atrapalha. Porque era pra ser uma integração entre as escolas, os alunos interagirem, mas isso não acontece, isso é só no papel. Chega lá é professor brigando com professor, desconfiando que um aluno tá com a idade trocada, desconfiando da credibilidade do professor e era pra ser cooperativo, era pra ser integralista, mas não consigo ver esse cunho nesses jogos ${ }^{8}$.

A participação do alunado nos Jogos Escolares também é utilizada como "moeda de troca", ou seja, como mecanismo disciplinador do comportamento do alunado. Isso só é possível pelo fato de que o modelo adotado é seletivo e excludente, onde a maior

7FRIZZO, Giovanni. Informação pessoal: entrevista Professor D. 2010. ${ }^{8} \mathrm{FRIZZO}$, Giovanni. Informação pessoal: entrevista Professora E. 2010.

Movimento, Porto Alegre, v. 19, n. 04, p. 163-180, out/dez de 2013. 
parte do alunado não participa das atividades, daí que há uma disputa entre o alunado para ser convidado pelo professor ou pela professora a participarem. Como podemos visualizar na figura abaixo, onde somente $32,5 \%$ dos estudantes já participaram de alguma destas competições esportivas.

Figura 1: participação nos jogos escolares: JERGS e Guri Bom de Bola (\%)

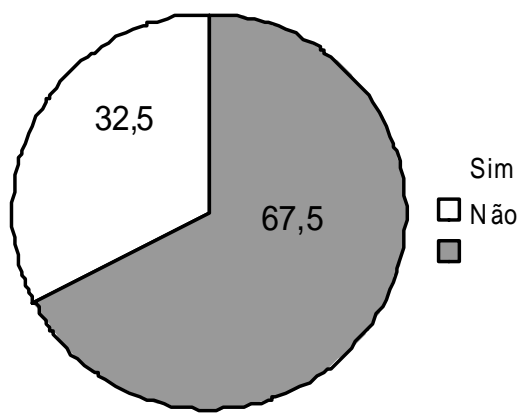

Fonte: respostas do alunado ao questionário

O relatos são bastante significativos neste sentido, pois como a motivação do alunado para participar dos jogos é bastante expressiva e poucos alunos e alunas podem participar, dada a lógica excludente destes tipos de competições, isso deve ser utilizado para "melhorar" o comportamento do alunado.

É interessante perceber o que o professorado afirma sobre a participação nos jogos escolares como "moeda de troca", pois o desejo do alunado em participar é muito grande, como nestes fragmentos das respostas ao questionário: "só participam os melhores jogadores"; "é muito bom ser escolhido. Bah! Eu fico muito feliz"; "é uma atividade legal porque mostra quem tem potencial, porque o professor te escolheu sendo que tem um monte"; "é a terceira melhor coisa que tem no ano, em segundo é o passeio de final de ano e em primeiro lugar vem a aprovação de ano". 
$\mathrm{O}$ professor $\mathrm{F}$ ressaltou a utilização deste mecanismo disciplinador para controlar o alunado, como se fosse um tipo de palmatória de outros tempos, o professorado estabelece como prérequisito à participação nos Jogos Escolares um número máximo de ocorrências indisciplinares na escola, independente do momento em que ela ocorreu, garantindo o controle durante todo o período em que o alunado está na escola, condicionando-o a se policiar para poder participar dos jogos,

[...] muitas direções e muitos professores de outras disciplinas, acabam excluindo o aluno desses JERGS ou dessas competições quando não está bem em alguma outra coisa: "Ah, tem três ocorrências, tu não vai participar do JERGS!". Não sei te dizer se isso é bom ou se isso é ruim, porque o aluno acaba se policiando um pouco mais, acaba se disciplinando, porque tem um objetivo para alcançar, talvez isso seja útil se olhar por esse lado. Mas acaba sendo uma troca: "Tu só vai se fizer isso! Tu só vai se fizer aquilo!"'

Estes dois elementos presentes na relação entre os Jogos Escolares e a educação física escolar: a competição e o disciplinamento de comportamentos, ao serem analisados sobre o viés da formação humana, são melhor compreendidos a partir da ênfase de Freitas (1995) sobre o processo de internalização de "mecanismos de eliminação" na escola, onde a avaliação é uma "categoria chave". Entretanto, segundo o autor, "a avaliação não está referida apenas à aprendizagem do conteúdo das disciplinas, mas é um potente instrumento de controle de sala de aula, tanto no que diz respeito ao comportamento (disciplina e motivação) como no que diz respeito à conformação de valores e atitudes" (FREITAS, 2002, p. 312-313). Tal como pudemos observar no fato de que o alunado condiciona seu comportamento dentro de determinados padrões e atitudes requisitados pelo ambiente escolar para ter a oportunidade de participar dos Jogos Escolares, como destacou o Professor G: "tem meninos que passam o ano inteiro esperando por

${ }^{9}$ FRIZZO, Giovanni. Informação pessoal: entrevista Professor F. 2010.

Movimento, Porto Alegre, v. 19, n. 04, p. 163-180, out/dez de 2013. 
isso e como isso vale tanto para eles, a gente tem que usar isso a nosso favor [...], seja qual era o problema, mesmo que fosse indisciplina com a professora de Português, Matemática, não serve, porque independente da disciplina é o comportamento dele." 10

Há uma determinada lógica avaliativa neste processo de seleção do alunado para participar das competições que operam na relação manutenção/eliminação. Nesse sentido, Freitas (1995, p. 239) salienta que "eliminação e manutenção são conceitos contrapostos, opostos, que evidenciam possíveis resultados de uma luta de contrários no bojo da seleção que o sistema de ensino abriga - a mando do sistema social". Ou seja, a eliminação daqueles alunos e alunas que não reúnem as condições técnicas e comportamentais para fazer parte das equipes esportivas escolares, traz embutida a manutenção destas condições como referência para o êxito escolar, ainda que sejam reafirmadas na disciplina de educação física, mas não somente nesta.

O êxito escolar aqui apontado refere-se não só a apropriação de conteúdos ou de conhecimentos, mas de uma aprovação social perante o coletivo escolar de que as habilidades esportivas adquiridas (não necessariamente nas aulas de educação física, mas também de experiências fora da escola) e o atendimento à padrões comportamentais requeridos produzem resultados positivamente reconhecidos. Embora, em um primeiro momento, esta assertiva possa parecer coerente com a lógica da formação escolar, ela entra em conflito ao verificar-se que este "êxito" está reservado para poucos, independente do atendimento aos requisitos necessários. Pois dada a lógica esportiva competitiva, "o acesso de todos à sua prática torna-se impossível, já que o esporte de alto rendimento segue os princípios da competição, do selecionamento e da produtividade" (SOUZA, 2009, p. 77-78).

A forma seletiva de inclusão nas equipes escolares que participam das competições esportivas internalizam, contraditoriamente, a exclusão no conjunto do alunado. Sob a luz dos conceitos de "inclusão excludente" e de "exclusão includente"

\footnotetext{
${ }^{10} \mathrm{FRIZZO}$, Giovanni. Informação pessoal: entrevista Professor G. 2010.
} 
proposta por Kuenzer (2005), é possível compreender este fenômeno de forma aprofundada. Pois, ao atender aos requisitos elaborados pela escola para a participação nos Jogos Escolares, um número restrito de alunos e alunas são contemplados na seleção das equipes escolares, ou seja, há uma inclusão da minoria excludente da maioria. Em última análise, se opera com a lógica da meritocracia implícita nos programas de ensino, em que somente os "melhores" são favorecidos e os "piores" são descartados. Isto é, a concorrência e a meritocracia são balizadores para a qualidade da escola, destaca-se que a competição como referência para a qualidade do ensino, expressão da meritocracia do atual projeto formativo na escola, pode ser observada também em diferentes competições, não somente vinculadas ao esporte, estabelecidas como políticas públicas, como a Olimpíada Brasileira de Matemática das Escolas Públicas e Olimpíada da língua Portuguesa, por exemplo.

Contraditoriamente, a exclusão de boa parte do alunado também envolve a internalização de uma perspectiva de comportamentos, atitudes e valores esperados que a tornam inclusivas, portanto, exclusão includente.

Importante destaque que fazemos, diz respeito ao fato de que essa lógica do esporte na escola não encontra um caminho consensual por todos os sujeitos, com pode ser verificado em uma passagem do relato do Professo F que aponta esta contradição.

Se eu pudesse, te confesso aqui, nunca faria torneio porque eu sou totalmente contra torneio, porque isso desperta muita competitividade e eu acho que a escola não é o ambiente correto pra isso, porque eles não estão sendo preparados para ser atletas de alto nível, acho que é extremamente importante competir, mas dá pra ter outra abordagem a competição, não simplesmente chegar, ser campeão e ganhar medalha ${ }^{11}$.

${ }^{11}$ FRIZZO, Giovanni. Informação pessoal: entrevista Professor F. 2010. 


\section{Considerações Finals}

Tendo em vista os elementos apresentados até aqui, identificase que a lógica esportiva na escola interpõe mecanismos de manutenção e eliminação como processos de avaliação da formação do alunado, internalizando a lógica da competição e da meritocracia. Onde se "naturaliza" uma determinada forma de ser que beneficia somente uma pequena parte do coletivo escolar.

O sistema esportivo, ao integrar-se ao projeto educativo da escola, adquire uma mesma perspectiva avaliativa de ranqueamento, de comparação e concorrência entre escolas e alunado, de disputas em que poucos se sobressaem atingindo níveis desejados e que são referência de qualidade do ensino e da formação com base na competitividade.

A motivação do alunado para a participação nos Jogos escolares são utilizados como um eficiente meio de disciplinar comportamentos e internalizar a competição em que somente os mais aptos, os mais capazes, os mais competentes são aqueles que vivenciarão experiências exitosas na escola. $\mathrm{O}$ fato de o alunado querer participar das competições fazem com que aceitem e obedeçam qualquer regra, isto não significa concordar com elas, apenas acatá-las para poder vislumbrar a participação nos Jogos, embora muitas vezes não seja possível porque mesmo obedecendo as regras, o caráter excludente e seletivo dos jogos não permitem que todos participem, sendo utilizado como "moeda de troca" na organização do trabalho pedagógico da educação física e internalizando mecanismos de manutenção e eliminação.

Pontuamos alguns elementos de síntese sobre a relação dos Jogos Escolares e a lógica do sistema esportivo integrada ao projeto formativo da escola atual. Retomando a identificação de que os Jogos Escolares oriundos de políticas públicas e privadas compartilham da mesma concepção, faz com que haja um entrelaçamento dos Jogos organizados pela esfera pública (como o caso dos JERGS) e da esfera privada (como o Guri Bom de Bola) como políticas educacionais. Embora tenhamos identificado algumas críticas à lógica 
competitiva na percepção do professorado sobre o caráter que se sobrepõe nos Jogos Escolares, identifica-se a competição exacerbada entre o alunado que busca vencer as competições acirrando disputas entre eles, pois as referências para os Jogos são as mesmas das competições institucionalizadas de alto rendimento.

Ressaltamos que nossas críticas aos Jogos Escolares, referemse ao modelo de Jogos analisados, cujos objetivos e finalidades não expressam interesses comuns e coletivos de formação. Necessitando, portanto, de alternativas para a realização de Jogos Escolares em que os sujeitos se sintam pertencentes e contemplados em sua totalidade, não operando nas dualidades inclusão/exclusão, manutenção/eliminação. 


\begin{abstract}
The School Games as Mechanisms for Maintenance and Elimination: a critique of the sportive logic in school

Abstract: This article aims to analyze the mechanisms of maintenance and elimination present in School Games, especially in the final grades of primary education, showing the sportive logic in the school integrated to the formative project school today. Through a qualitative research study in municipal schools of Nova Santa Rita, we analyze the School Games that make up the school calendar this school system, identifying the sportive logic integrated to the educational project at school.

Keywords: Physical Education. School. School Games
\end{abstract}

Los Juegos Escolares como Mecanismos de
Manutención y Eliminación: una crítica a la lógica
deportiva en la escuela
Resumen: Ese artículo tiene por objetivo hacer un
análisis de los mecanismos de mantenimiento y
eliminación presentes en los Juegos escolares, sobre
todo en los últimos grados de la primaria en la Educación
Básica, evidenciando la lógica deportiva en la escuela
integrada al proyecto formativo escolar en la
actualidad. A través de una investigación de carácter
cualitativo en la red de enseñanza de la ciudad de
Nova Santa Rita, analizamos los Juegos Escolares
que componen el curso escolar, identificando la lógica
deportiva integrada al proyecto educativo en la
escuela.
Palabras-clave: Educación Física. Escuela. Juegos
Escolares




\section{REFERÊNCIAS}

BRACHT, Valter. Sociologia Crítica do Esporte: uma introdução. 3. ed. rev. ljuí: Unijuí, 2005.

FREITAS, Luiz Carlos de. Crítica da organização do trabalho pedagógico e da didática. Campinas: Papirus, 1995.

FREITAS, Luiz Carlos de. A internalização da exclusão. Revista Educação \& Sociedade, Campinas, v. 23, n. 80, p. 301-327, out. 2002.

GURI BOM DE BOLA. Regulamento Geral - 2010. Porto Alegre: [s.n.], 2010.

HILDEBRANDT-STRAMANN, Reiner. Textos pedagógicos sobre o ensino da educação física. ljuí: Unijuí, 2001.

JOGOS ESTUDANTIS DO RIO GRANDE DO SUL. Regulamento Geral - 2010. Porto Alegre: SEC-RS, 2010.

KUENZER, Acácia. Exclusão Includente e Inclusão Excludente: a nova forma de dualidade estrutural que objetiva as novas relações entre educação e trabalho. In: LOMBARDI, José Claudinei; SAVIANI, Dermeval; SANFELICE, José Luís.

Capitalismo, trabalho e educação. 3. ed. Campinas: Autores Associados, 2005.

KUNZ, Eleonor. Transformação didático-pedagógica do esporte. 6. ed. Ijuí: Unijuí, 2004.

OLIVEIRA, Sávio Assis de. Reinventando o esporte: possibilidades da prática pedagógica. Campinas: Autores Associados, 2001.

SOARES, Carmem et al. Metodologia do ensino da educação física. Rio de Janeiro: Cortez, 1992.

SOUZA, Maristela. Esporte escolar: possibilidade superadora do plano da cultura corporal. São Paulo: Ícone, 2009.

Endereço para correspondência:

Giovanni Frizzo

R. Andrade Neves, 1195, ap. 402. Centro -

Pelotas/RS

Recebido em: 10.04.2013

Aprovado em: 08.08.2013 